\title{
A importância da informação contábil no processo de tomada de decisão nas micro e pequenas empresas
}

\section{The importance of accounting information in the process of decision making in micro and small companies}

\section{Rafael de Lacerda Moreira}

Mestre em Ciências Contábeis pela Universidade Federal de Minas Gerais

Professor do Curso de Ciências Contábeis da Universidade Federal do Espírito Santo

Endereço: Av. Fernando Ferrari, no 514, Bairro Goiabeiras

CEP: 29075-910 - Vitória/ES - Brasil

E-mail: rafael.1.moreira@ufes.br

Telefone: (27) 4009-2602

\section{Luana Vogel Encarnação}

Graduada em Ciências Contábeis pela Universidade Federal dos Vales do Jequitinhonha e Mucuri Endereço: João Moreira Vilela, no 69, Bairro Joaquim Pedrosa

CEP: 39804-711 - Teófilo Otoni/MG - Brasil

E-mail: luanavogelds@hotmil.com

Telefone: (33) 9199-0911

\section{Oscar Neto de Almeida Bispo}

Mestre em Ciências Contábeis pela Universidade Federal de Minas Gerais

Professor do Curso de Ciências Contábeis da UFVJM

Endereço: Rua do Cruzeiro, no 01, Bairro Jardim São Paulo

CEP: 39803-371 - Teófilo Otoni/MG - Brasil

E-mail: oscar.almeida@ufvjm.edu.br

Telefone: (33) 3522-6037

\section{Marcello Angotti}

Mestre em Ciências Contábeis pela Universidade Federal de Minas Gerais

Professor da Universidade Federal de São João del Rei - MG

Endereço: Campus Tancredo Neves - UFSJ .

CEP: 36.301-360. São João del Rei/MG - Brasil

E-mail: angotti@ufsj.edu.br

Telefone: (31) 8455-2500

\section{Romualdo Douglas Colauto}

Doutor em Engenharia de Produção pela Universidade Federal de Santa Catarina

Professor da Universidade Federal do Paraná

Av. Prefeito Lothário Meissner, no 632 - Bairro Jardim da Penha

CEP: 80210-170. Curitiba/PR - Brasil

E-mail: rdcolauto@ufpr.br

Tel: (41) 3360-4411 / (41) 9918-0617

Artigo recebido em 09/05/2012. Revisado por pares em 28/10/2012. Reformulado em 05/02/2013. Recomendado para publicação em 18/02/2013 por Sandra Rolim Ensslin (Editora Científica). Publicado em 30/04/2013. 


\title{
Resumo
}

O objetivo deste trabalho consiste em avaliar a percepção dos gestores sobre a importância atribuída às informações contábeis e sua utilização nos negócios. Para isso fez-se pesquisa de campo na cidade de Teófilo Otoni/MG, tendo como amostra as micro e pequenas empresas ligadas ao comércio varejista. Concluiu-se que a Contabilidade é vista como mera executora das obrigações fiscais e trabalhistas, assim os gestores não percebem a importância da informação contábil Constatou-se ainda que os gestores, com maior nível de formação, compreendem a relevância da Contabilidade, mas não manteriam o contador caso houvesse uma simplificação no recolhimento dos tributos.

Palavras-chave: Micro e Pequenas Empresas. Controle Gerencial. Informações Contábeis.

\begin{abstract}
The objective of this paper is to assess the perception of managers about the importance attached accounting information and its use in business. For this we used a field research in the city of Teófilo Otoni, MG, with a sample of micro and small companies linked to the retail trade. We conclude that the accounting is view as a mere executor of tax and labor obligations, , so managers do not perceive the importance of accounting information. We also acknowledge that managers with higher levels of education, understand the relevance of accounting, but not keep the accountant if there is a simplification in the collection of taxes.
\end{abstract}

Keywords: Micro and Small Enterprises. Management Control. Accounting Information.

\section{Introdução}

A informação pode ser vista como um instrumento para lidar com problemas relacionados à administração de empreendimentos, pois, em cenários competitivos, onde os gestores se deparam a todo o momento com a necessidade de tomar decisões, aqueles que souberem aplicá-la de forma eficaz podem alcançar posição de destaque diante dos concorrentes.

O fator decisório é questão de pesquisa tanto para grandes quanto para as micro empresas (MPEs) e tem requerido atenção dos gestores, devido à complexidade de avaliação e resolução de problemas diários. Esse aspecto remete à necessidade de informações concretas que supram a carência informacional e administrativa dos gestores.

As MPEs se configuram como agentes dinâmicos na geração de atividades diversas e inovadoras e vêm apresentando grande importância na economia, não somente no Brasil, mas em todo o mundo. Segundo Baty (1994), as pequenas empresas possuem substancial importância na evolução das sociedades, contribuindo para os desenvolvimentos econômicos, sociais e políticos das nações. Essa contribuição é percebida na realidade cotidiana, resultante da representatividade que as MPEs possuem na geração de empregos, produção e comercialização de bens e serviços que suprem as necessidades básicas, contribuindo para o desenvolvimento e a dinâmica da economia (CANECA et al., 2009). 
Por outro lado, Stroeher (2005) complementa que a estrutura das micro e pequenas empresas cria uma condição particular que a diferencia das empresas de maior porte, o que torna necessário um estudo com enfoque diferenciado para a sua gestão, por apresentarem problemas próprios, além de possuírem uma grande heterogeneidade. As dificuldades e as restrições encontradas nas MPEs referem-se ao acesso a crédito, à elevada carga tributária, à falta de mão-de-obra especializada e, principalmente, à compreensão dos aspectos financeiros e contábeis do negócio.

Para Stroeher (2005), a não compreensão da lógica contábil transforma, muitas vezes, os relatórios financeiros preparados pelo contador em mero cumprimento das obrigações legais, em vez de suprir o administrador ou o proprietário com informações úteis para o processo de tomada de decisões.

Estudos realizado pelo SEBRAE (2007) e por pesquisas nacionais e internacionais (KNAUP, 2005; EVERETT; WATSON, 1998; SMITH, 1999; LUCENA, 2004; CANECA et al., 2009), apontam que as MPEs vêm apresentando altos índices de mortalidade no decorrer dos anos, pois têm encontrando dificuldades em questões administrativas, financeiras, burocráticas, além da falta de conhecimentos específicos que possam auxiliar os gestores em sua área de atuação.

A fragilidade dessas empresas associada à falta de informações contábil-financeiras em seu processo de decisão faz com que estas tendam a apresentar uma situação de maior risco diante da concorrência, o que remete à necessidade de um controle mais eficaz que permita decisões mais estruturadas, de modo a conduzir à obtenção de melhores resultados.

Nesse contexto, Atkinson et al. (2000) salientam que a Contabilidade possui o papel de gerar informações ao empresário de modo a favorecer tomadas de decisões mais acertadas e em tempo hábil. Horngren, Sundem e Stratton (2006) complementam que o objetivo básico da informação proveniente da Contabilidade é o de auxiliar seus diversos usuários no processo decisório, sendo importante para isso que tais informações sejam compreendidas de forma concreta, para que possam contribuir para um melhor resultado.

Diante desses fatos, a questão que norteia o estudo é esta: De que modo os gestores das MPEs percebem a importância das informações contábeis como um recurso gerencial para suporte à gestão de seus negócios? Nesse sentido, o trabalho tem por objetivo avaliar a percepção dos gestores das Micro e Pequenas Empresas de Teófilo Otoni sobre a relevância da informação contábil no gerenciamento de seus negócios e no suporte à tomada de decisões. De forma específica, busca-se avaliar a importância atribuída ao contador e aos serviços contábeis; avaliar a relação entre o perfil do gestor e sua percepção sobre a importância da utilização da informação contábil-gerencial e verificar se os serviços contábeis prestados às empresas de Teófilo Otoni garantem um suporte adequado ao processo decisório.

O estudo está estruturado em quatro seções, além desta introdução. Inicialmente, apresenta-se a plataforma teórica, focando os estudos semelhantes e uma sucinta contextualização sobre as MPEs. Após, mostram-se os procedimentos metodológicos. Na seção seguinte, são apresentados os resultados do estudo e, por fim, as inferências conclusivas.

\section{Plataforma Teórica}


Entre as diversas mudanças que vêm ocorrendo nos mercados mundiais, pode-se destacar o crescimento acelerado de micro e pequenas empresas (BATY, 1994; SCHELL, 2000). Segundo o SEBRAE (2009), essas empresas respondem por grande parcela da economia nacional, representando $98,9 \%$ dos estabelecimentos no Brasil, $39,6 \%$ dos empregos, e por $1,3 \%$ de participação nas exportações, o que as torna de fundamental importância para a economia interna e externa.

Por outro lado, a taxa de mortalidade empresarial foi 25\%, entre 2003 e 2005, para estabelecimentos com até dois anos de existência. Uma parcela de responsabilidade pelo fechamento dessas empresas diz respeito ao gestor e ao tipo de administração empregada, pois elas possuem uma administração ainda pouco especializada e, muitas vezes, é familiar, não possuindo condições de realizar uma análise mais aprofundada do seu empreendimento, necessitando, portanto, dispor de informações gerenciais que as auxiliem a sobreviver no mercado (SEBRAE, 2007).

Se, por um lado, a informação contábil é importante na tomada de decisão empresarial, muitos usuários não conseguem compreender as informações veiculadas por meio dos demonstrativos contábeis por não conhecerem o significado de muitos termos que são utilizados na evidenciação de eventos econômicos e financeiros. Esse fato tem contribuído para uma precária interpretação das informações fornecidas nesses relatórios. Assim, essas informações não têm contribuído com a finalidade a que se propõem, que é o de comunicação dos eventos econômicos (DIAS FILHO, 2000).

A falta de habilidade para entender e manusear os artefatos fornecidos pela Contabilidade nas MPEs é uma das dificuldades encontradas em muitas pesquisas (SHELDON, 1994; MORAIS, 1999; ALBURQUERQUE, 2004; LUCENA, 2004; MIRANDA et al., 2008), e isso acaba por gerar uma cultura de não utilização da informação contábil nessas empresas.

Lima et al (2004) verificaram que a maioria dos gestores não utiliza as informações contábeis na administração do negócio, motivados principalmente pelo não entendimento dos benefícios que poderiam trazer na gestão da empresa e, devido a esse fato, considera a Contabilidade apenas como uma despesa a mais e que não agrega valor ao empreendimento.

Segundo Flippo e Musinger (1970), os gestores atuam limitados pelo volume e pela qualidade de dados disponíveis, por sua habilidade para acessá-los e, sobretudo, por sua capacidade de analisá-los. O sucesso de um gerente pode ser medido pela qualidade e pela quantidade de suas decisões, que vão depender de sua eficiência na utilização de informações.

Stroeher e Freitas (2006) complementam que, devido ao pequeno empresário, na maioria dos casos, não possuir os conhecimentos contábeis suficientes, por vezes, não conseguem avaliar a sua importância. Segundo os autores, os empresários estão mais preocupados com as informações de ordem tributária fornecidas pela Contabilidade, relacionando o contador a questões tributárias, como mecanismos para escapar da tributação, deixando de lado o planejamento, a organização, o controle, e outras atribuições básicas da função administrativa.

Albuquerque (2004) levanta ainda um grave problema no processo de gerenciamento das MPEs: observou que boa parte das decisões é tomada com base na intuição e experiência do gestor, e não de uma análise pormenorizada das informações financeiras e mercadológicas. Assim, caberia ao contador estreitar uma aproximação, participar e conhecer mais a vida empresarial de seus clientes e demonstrar com convicção a relevância da Contabilidade para uma adequada gestão empresarial. 
Ainda sobre os benefícios da informação contábil, Krafta e Freitas (2008), Cragg e Zinatelli (1995) e Igbaria e Zinatelli (1997) ressaltam que os pontos deficitários podem ser melhorados por meio da melhor gestão da informação, com base em dados que, muitas vezes, já estão disponíveis na empresa e não são explorados de forma adequada. Os autores alertam para a importância da Tecnologia de Informação (TI) nas MPEs como ferramenta de auxílio à gestão, sendo que sistemas mais enxutos e facilmente integrados seriam os ideais para elas, o que poderia ser facilitado caso a empresa fizesse a Contabilidade internamente.

Nunes e Serrasqueiro (2004) constataram, em empresas portuguesas, que os empresários que elaboram a Contabilidade internamente dão maior importância à informação gerada por ela e levantam a hipótese que, quando a Contabilidade é feita externamente, a principal finalidade será para propósitos fiscais e legais. Verificaram ainda que o nível de formação do empresário exerce influência na elaboração da Contabilidade interna ou externamente.

Congruente ao fato, Oliveira, Muller e Nakamura (2000) notaram que existe associação moderada entre a formação acadêmica e a utilização da informação contábil na gestão em pequenas empresas. Os resultados apontaram que os profissionais com formação acadêmica na área de Ciências Sociais Aplicadas utilizam as informações geradas pelo Sistema de Informação Contábil com maior intensidade.

Algumas pesquisas demonstraram a disposição de os gestores pagarem mais aos escritórios de Contabilidade por um serviço que contenha informações que ajudam a gestão na tomada de decisões administrativas (MIRANDA et al., 2008; CANECA et al., 2009). Desse modo, Caneca et al. (2009) advertem que, caso os escritórios contábeis melhorassem seus serviços, buscando sanar a necessidade de informação, haveria manutenção e aumento de clientes e, consequentemente, mais valorização dos serviços contábeis.

Citam-se outros estudos já realizados a respeito da utilidade da Contabilidade nas MPEs. Ramos, Paula e Teixeira (2000) demonstraram que os pequenos empresários, clientes de escritórios da cidade de Ipatinga, Minas Gerais, veem na Contabilidade um simples instrumento de registro para atendimento das exigências fiscais. Pires, Costa e Hahn (2004) encontraram resultados semelhantes na cidade de Glória, Espírito Santo, onde os escritórios não atendem satisfatoriamente às necessidades dos clientes. Miranda et al. (2008) observaram que grande parte dos gestores de pequenos "mercadinhos" na periferia de Recife, Pernambuco, ainda percebe os contadores apenas como provedores de serviços relacionados ao recolhimento dos impostos e dos encargos sociais.

Bernardes e Miranda (2011) analisaram o papel da informação contábil nas histórias de sucesso e insucesso em quatro empresas de serviço. Os referidos autores verificaram que gestores e contadores têm interesse apenas no que se refere a recolhimentos de tributos, e, com exceção da empresa de maior sucesso que utiliza certo conjunto de informações gerenciais, as demais não utilizam informações gerenciais e se preocupam exclusivamente com o caixa em uma visão de curto prazo. Silva et al. (2010) buscaram evidências sobre a forma como a informação contábil é utilizada pelas micro e pequenas empresas. Foram realizadas entrevista com gestores de 55 empresas localizadas na região metropolitana do Recife (PE). Verificou-se que, na maioria dos casos, os relatórios disponibilizados são os mais tradicionais e menos sofisticados e que a maioria dos gestores não utiliza a Contabilidade para acompanhar metas, medir desempenhos e avaliar impactos financeiros de suas decisões, deixando assim de fazer uso gerencial dos relatórios. 
Por outro lado, Oliveira, Muller e Nakamura (2000) realizaram uma pesquisa em 29 empresas do Paraná do ramo de retíficas de motores, com o intuito de analisar o estilo de administração predominante e a influência deste na utilização de tais informações como ferramenta de apoio à tomada de decisões. A maioria das empresas estudadas eram empresas familiares (65\%), onde se constatou que $90 \%$ das empresas utilizam o sistema de informação contábil para atendimento das necessidades administrativas não só de cunho fiscal, mas também gerencial e, conforme ressaltam os autores, "contrariando o quase senso comum", a pesquisa revelou uma predominância (55\%) da utilização do SIC para fins gerenciais.

Nesse contexto, justificam-se mais estudos sobre o tema, visto que se torna clara a necessidade de um suporte contábil que possa auxiliar os gerentes a tomar suas decisões baseados na realidade do seu negócio. De certa forma, as MPEs são pouco estudadas, bem como seu processo de geração e utilização de informações para tomada de decisão, a importância dada à Contabilidade e a forma como são administradas.

\section{Metodologia da Pesquisa}

Este trabalho se caracteriza como uma pesquisa descritiva por buscar descrever e apresentar uma visão da utilização da Contabilidade no apoio às decisões gerenciais no comércio varejista da cidade de Teófilo Otoni. Apresenta caráter tanto qualitativo como quantitativo. É qualitativo por abordar a opinião dos micro e pequenos empresários a respeito da importância das informações contábeis e ao grau de sua utilização em seus processos diários, por meio de questionamentos que avaliam, no geral, o perfil e a percepção destes a respeito dos benefícios gerenciais que poderão ser obtidos com a utilização de informações contábeis para o suporte às decisões. É quantitativo, porque foram traduzidas em números as opiniões e as informações coletadas dos empresários.

\subsection{Definições da Amostra}

O objeto de estudo são as micro e pequenas empresas ligadas ao comércio varejista de Teófilo Otoni. A cidade é considerada centro macrorregional e situa-se no nordeste do Estado de Minas Gerais, no Vale do Mucuri, dispondo de um comércio diversificado e movimentado, pois apresenta grande quantidade de empresas ligadas ao comércio varejista, o que contribui para a movimentação da economia local e regional. Além disso, a cidade faz sucesso no comércio de pedras preciosas, sendo denominada "Capital das Pedras Preciosas".

A escolha da cidade se deu por dois fatores: (i) o fato de nela se inserir a Universidade Federal do Vale do Jequitinhonha e e do Vale do Mucuri, existindo, dessa forma, mais disponibilidade dos empresários em colaborar em investigações desenvolvidas pelos membros da Universidade; e (ii) restrição orçamentária, considerando primeiro os diálogos realizados com os gestores. Além disso, deseja-se utilizar, como instrumento de coleta de dados, questionários aplicados pessoalmente aos gestores e, desse modo, não haveria possibilidades de estender a pesquisa a empresas de outras localidades.

É importante ressaltar que o questionário poderia ter sido enviado para empresas de outras localidades pela internet ou por correio, mas foi feito uma escolha em não utilizar essa possibilidade por não se ter conhecimento sobre o emprego de tecnologia por essas MPEs, bem como disponibilidade de colaboração com a pesquisa, caso essa tivesse sido a escolha. 
De certo, a aproximação e o diálogo com os gestores possibilitaram maior riqueza nas observações e conclusões.

Para a realização do estudo de campo, inicialmente foram obtidas informações a respeito do número de MPEs existentes na cidade, no Sindicato do Comércio Varejista de Teófilo Otoni (Sindcomercio), que revelou haver, na cidade, cerca de 2.000 MPEs. Assim, optou-se por uma amostra composta por 200 empresas, sendo esta fornecida de modo aleatório pelo próprio Sindcomercio com base em seus registros. O critério para a classificação do porte dessas empresas foi aquele adotado pelo SEBRAE, em que são classificadas como micro as empresas comerciais que possuem até nove empregados, e empresas de pequeno porte aquelas que apresentam de 10 a 49 funcionários, o que visa proporcionar um padrão confiável, pois as informações não estavam disponíveis pelo critério de faturamento.

\subsection{Coleta e Tratamento de Dados}

Foi realizada pesquisa de campo por meio de questionário para se coletarem os dados, sendo composto por questões tanto abertas quanto fechadas, entregues pessoalmente em cada empresa. Foi feito um pré-teste antes da aplicação definitiva do questionário, que abrangeu sete empresas da cidade escolhida de modo aleatório entre a amostra. Após a entrega dos 200 questionários às empresas constantes da amostra, foi obtido um retorno de 146 questionários, representando $73 \%$ da amostra.

Parte dos dados obtidos nos questionários pôde ser triangulada com opiniões oriundas dos diálogos feitos com alguns gestores que se propuseram a discutir melhor o tema de pesquisa. Assim, foi possível realizar a análise de discurso dos respondentes, que consiste em incluir as opiniões verbalmente relatadas de modo informal pelos participantes da pesquisa. Durante o recolhimento dos questionários, muitos gestores relatavam informações adicionais a respeito das perguntas que compunham o questionário, informações estas que serviram de base para acrescentar pontos importantes durante a análise, de modo a contribuir para mais esclarecimentos do trabalho. Os pontos considerados importantes, obtidos dos diálogos com os gestores, eram registrados em uma parte descritiva do questionário no momento da coleta.

$\mathrm{Na}$ tabulação, utilizou-se o Microsoft Excel para as estatísticas descritivas com a elaboração de tabelas e gráficos analíticos. Para verificar os possíveis níveis de correlação entre as variáveis da pesquisa, procedeu-se a uma análise de correlação pelo método de Spearman e de frequência combinada, ambos por meio do Software Stata ${ }^{\circledR}$.

A correlação foi calculada com valores relativos das variáveis, por exemplo, ao ser perguntado sobre sua faixa de idade, o entrevistado teve cinco opções, sendo elas: 18 a 24 anos, 25 a 30 anos, 30 a 39 anos, 40 a 49 anos, e mais de 50 anos. A cada opção foi dado um valor de um a cinco, e, com esse valor relativo, foi calculada a correlação. Nas demais variáveis, em que foram analisadas correlações, utilizou-se processo semelhante.

O coeficiente $\rho$ de Spearman mede a intensidade da relação entre variáveis ordinais. Usa, em vez do valor observado, apenas a ordem das observações. Desse modo, esse coeficiente não é sensível a assimetrias na distribuição, nem à presença de outliers, não exigindo, portanto, que os dados provenham de duas populações normais.

Logo após, foram estimadas regressões lineares para possibilitar inferências causais entre relações de variáveis em que foi percebido algum tipo de correlação. Na Equação 1, averiguou-se a existência de causalidade das variáveis relacionadas à tecnologia de 
informação (número de computadores, tipos de programas e nível de informatização) em variáveis que impactam em gastos para a empresa (número de empregados ou disposição em pagar mais ao contador por informações gerenciais).

Equação 1:

$$
\mathrm{Y}_{\mathrm{i}}=\beta_{0}+\beta_{1} \mathrm{TI}_{\mathrm{i}}+\varepsilon_{\mathrm{i}}
$$

Em que: $\mathrm{Y}_{\mathrm{i}}$ é a variável que impacta em custo para empresa $\mathrm{i}$, onde, dependendo da especificação, a variável Y é substituída pela variável NE que representa o número de empregados (V9) ou DP que representa a disposição em pagar mais por informações gerenciais (V25); A variável TI representa as variáveis da tecnologia da informação e dependendo da especificação, a variável TI é substituída pelas variáveis: NC; que se refere ao número de computadores da empresa (V12); TP, que se refere aos tipos de programas utilizados (V13); e NI que é o nível de informatização da empresa (V14); e $\varepsilon_{\mathrm{i}}$ é o termo de erro. Cabe ressaltar que a denominação das variáveis tem a ver com o número da pergunta no questionário, por exemplo, a variável V9 foi a nona pergunta feita no questionário.

Após, foi estimada, conforme Equação 2, a regressão em que a importância atribuída às informações contábeis é dependente das variáveis referentes (i) ao nível de informatização; (ii) se as informações contábeis suprem as necessidades dos gestores; e (iii) se os gestores manteriam os contadores caso houvesse simplificação na parte fiscal.

Equação 2:

$$
\mathrm{IA}_{\mathrm{i}}=\beta_{0}+\beta_{1} \mathrm{NI}_{\mathrm{i}}+\beta_{2} \mathrm{IC}_{\mathrm{i}}+\beta_{3} \mathrm{MC}_{\mathrm{i}}+\varepsilon_{\mathrm{i}}
$$

Em que: $\mathrm{IA}_{\mathrm{i}}$ é a importância atribuída a informação contábil (V22); $\mathrm{NI}_{\mathrm{i}}$ é o nível de informatização da empresa (V14); $\mathrm{IC}_{\mathrm{i}}$ é uma variável binária onde os gestores avaliaram se a informação contábil que recebem supre as suas necessidades (V23); $\mathrm{MC}_{\mathrm{i}}$ é outra variável binária onde os gestores avaliaram se manteriam o contador caso houvesse simplificação fiscal (V24); $\varepsilon_{\mathrm{i}}$ é o termo de erro.

$\mathrm{Na}$ Equação 3, procuraram-se relações causais entre a manutenção do contador, caso houvesse simplificação fiscal com o nível de escolaridade dos gestores e o nível de informatização das micro e pequenas empresas.

Equação 3:

$$
\mathrm{MC}_{\mathrm{i}}=\beta_{0}+\beta_{1} \mathrm{EG}_{\mathrm{i}}+\beta_{2} \mathrm{NI}_{\mathrm{i}}+\varepsilon_{\mathrm{i}}
$$

Em que: $\mathrm{MC}_{\mathrm{i}}$ e $\mathrm{NI}_{\mathrm{i}}$ possuem a mesma definição adotada na Equação 2. A variável $\mathrm{EG}_{\mathrm{i}}$ representa a escolaridade do gestor (V6). Além disso, foram feitos testes de relaxamento dos pressupostos básicos de regressão linear em todas as equações estimadas. Nos casos em que as regressões não foram homecedásticas, foram reestimadas com correção de robustez para heterocedasticidade.

\section{Análise dos Resultados}

\subsection{Caracterização dos Respondentes}

No que diz respeito ao cargo ocupado pelos participantes da pesquisa, constata-se que $66,4 \%$ fazem parte do quadro acionário (proprietário ou sócio). Os demais 30,8\% 
classificaram-se como gerentes e administradores, além de um pequeno número $(2,7 \%)$ que não descreveu o cargo que ocupa na empresa.

Na Tabela 1, apresenta-se a estatística descritiva relativa ao nível de escolaridade dos respondentes da amostra. A pesquisa revela que $11 \%$ dos gestores se encontram cursando o nível superior, $32,9 \%$ já possuem o nível superior completo e deste total destaca-se que $25 \%$ são graduados em direito, e 8,3\%, em administração, o que contribui de forma direta ou indireta a melhor compreensão dos aspectos relacionados ao gerenciamento do seu negócio, a maioria dos gestores $(40,4 \%)$ possui o segundo grau completo.

Tabela 1- Nível de escolaridade

\begin{tabular}{lcc}
\hline \multicolumn{1}{c}{ Nível de Escolaridade } & Frequência & \% \\
\hline $1^{\circ}$ grau incompleto & 8 & 5,5 \\
$1^{\circ}$ grau completo & 3 & 2,1 \\
$2^{\circ}$ grau incompleto & 11 & 7,5 \\
$2^{\circ}$ grau completo & 59 & 40,4 \\
Nível superior incompleto & 16 & 11 \\
Nível superior completo & 48 & 32,9 \\
Não opinaram & 1 & 0,7 \\
Total & $\mathbf{1 4 6}$ & $\mathbf{1 0 0 , 0}$ \\
\hline
\end{tabular}

Fonte: Dados da Pesquisa.

A maior parcela dos respondentes apresenta um nível de escolaridade satisfatório, mas a pesquisa ainda constatou pequeno número de indivíduos com nível baixo de escolaridade ( $1^{\circ}$ Grau Incompleto).

A respeito da existência de conhecimentos anteriores, a abertura do seu negócio, $71 \%$ afirmaram possuir experiência na área empresarial, ou seja, mais da metade dos componentes da pesquisa detinham o conhecimento das atividades empresariais ao abrir o seu negócio. Esse é um ponto positivo no sentido de garantir mais familiaridade do gestor com os processos gerenciais, contribuindo para que esses micro e pequenos negócios consigam maiores chances de sobrevivência.

O percentual de $27 \%$ diz respeito aos indivíduos que alegaram não possuir experiência no ramo. Esse número não se apresenta elevado, porém se torna considerável ao passo que esses gestores, mesmo sem possuírem experiência na atividade empresarial, arriscam na constituição do próprio negócio. Segundo Leitão (2009), entre as características que devem possuir os gestores para garantir o sucesso nos negócios está a necessidade de se ter um bom conhecimento do mercado em que atua. Dessa forma, a falta de conhecimento prévio das atividades a serem desenvolvidas se caracteriza como um dos fatores que pode contribuir muitas vezes para a mortalidade dessas empresas, sendo necessário a qualquer indivíduo que pretenda abrir um negócio o conhecimento dos aspectos diretamente relacionados com a operação a ser desempenhada.

\subsection{Caracterização das Empresas da Amostra}

Para classificar as empresas pelo porte, foi utilizado o critério do SEBRAE, com base no número de empregados. De acordo com esse critério, as microempresas comerciais são aquelas que possuem até nove empregados, e as pequenas empresas são aquelas que 
apresentam de 10 a 49 empregados. Entre as empresas da amostra, 73,97\% são microempresas, e $21,23 \%$ são classificadas como de pequeno porte conforme a Tabela 2.

Os gestores foram solicitados a classificar suas empresas de acordo com o porte, sendo apresentadas as seguintes alternativas: microempresa e empresa de pequeno porte. Ao confrontar as respostas obtidas na pesquisa com a classificação do SEBRAE, verifica-se uma considerável divergência em 33 empresas, em que 20 respondentes classificaram seus negócios como de pequeno porte, quando, pelo critério do SEBRAE, essas empresas seriam classificadas como microempresa. Ocorreu também que 13 gestores classificaram seus negócios como microempresa ao passo que elas se enquadrariam como de pequeno porte.

Tabela 2 - Porte da empresa

\begin{tabular}{lcc}
\hline \multicolumn{1}{c}{ Porte/ Número Empregados } & Frequência & \% \\
\hline Microempresa (até 9 empregados) & 108 & 73,97 \\
Empresa de Pequeno Porte (de 10 a 49) & 31 & 21,23 \\
Não opinaram & 7 & 4,79 \\
Total & $\mathbf{1 4 6}$ & $\mathbf{1 0 0 , 0}$ \\
\hline
\end{tabular}

Fonte: Dados da pesquisa.

Essas diferenças resultam das classificações feitas pelos gestores, que levam em consideração o faturamento bruto obtido em seu negócio, sendo esse critério divergente do do SEBRAE que considera apenas o número de funcionários, o que não permite, na maioria dos casos, um alinhamento entre as classificações. Isso proporciona uma confusão na classificação das empresas.

Os dados da Tabela 3 apontam o tempo de funcionamento das empresas da amostra.

Tabela 3 - Tempo de funcionamento da empresa

\begin{tabular}{lcc}
\hline \multicolumn{1}{c}{ Idade da Empresa } & Frequência & \% \\
\hline Menos de 1 ano & 14 & 9,6 \\
De 1 a 3 anos & 23 & 15,8 \\
De 4 a 6 anos & 22 & 15,1 \\
De 7 a 9 anos & 12 & 8,2 \\
10 anos ou mais & 75 & 51,4 \\
Total & $\mathbf{1 4 6}$ & $\mathbf{1 0 0 , 0}$ \\
\hline
\end{tabular}

Fonte: Dados da pesquisa (2010).

Verifica-se que existem 75 estabelecimentos com 10 anos ou mais de existência na cidade. Isso demonstra, segundo Queiroz (2005), que as empresas que atuam com mais de 10 anos no mercado se encontram acima da média nacional, sendo essa longevidade atribuída à dedicação que seus proprietários demonstram ao tentar promover o desenvolvimento de seus negócios, na busca pelo sustento e paralelamente contribuir para o progresso econômico de sua região.

Por fim, há 23 empresas com tempo de funcionamento de 1 a 3 anos. Ainda se percebe um número considerável de novas empresas sendo constituídas, sendo 14 estabelecimentos com menos de 1 ano de atividade. É importante que essas empresas possuam um acompanhamento sistemático de suas operações, pois, de acordo com Queiroz (2005), os 
primeiros anos são cruciais para os microempresários, visto que, quanto mais recentes são essas empresas, maiores se apresentam os riscos de mortalidade.

\subsection{Processo Decisório e Percepção do Valor dos Contadores}

Neste tópico, serão analisados os recursos que os micro e pequenos empresários utilizam com maior frequência para subsidiar o processo decisório. Em seguida, será verificada a importância atribuída ao profissional contador e às informações que são produzidas por ele, além de se verificar se essa assessoria tem atendido às necessidades das empresas.

Os dados mostram que $64,4 \%$ dos gestores confiam na própria experiência, considerando esta importante no momento de lidar com as situações adversas do dia a dia. Em seguida, a pesquisa de mercado é apontada por $32,4 \%$ dos respondentes, o que mostra que estes se preocupam em obter informações sobre o mercado e suas variações como estratégia para se posicionar melhor diante de seus concorrentes. Utilizam também relatórios contábeis, $(22,6 \%)$ como fonte de decisão.

Interessante ressaltar que $11,6 \%$ tomam suas decisões de gerenciamento com base na intuição, o que nem sempre favorece uma base sólida e confiável para que o gestor possa definir padrões corretos de decisão. Existem ainda 14,4\% que afirmaram utilizar relatórios preparados manualmente como suporte à decisão. Esse aspecto chama atenção visto que, em uma época de grande acessibilidade aos computadores, esses gestores processam a informação de forma intuitiva ou manual, sem o auxílio do computador, conforme a Figura 1.

Figura 1 - Recursos Utilizados para a Tomada de Decisões

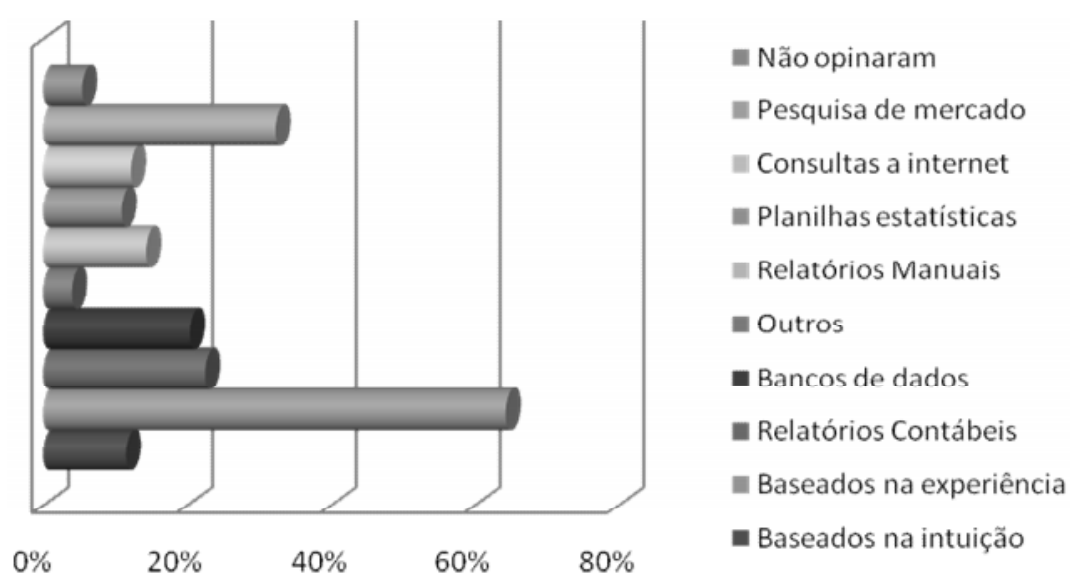

Fonte: Dados da pesquisa.

Outro ponto que a pesquisa revela é que 49,20\% dos gestores apontaram o administrador como o profissional mais indicado para realizar o controle e a avaliação da empresa, sendo este um indicativo de que o contador não é reconhecido pela maioria dos gestores como um profissional que produz informações úteis para a empresa. Somente 29,2\% reconheceram a importância do contador para a avaliação do desempenho de suas empresas (Tabela 4). 
Tabela 4 - Profissional que contrataria para avaliar e controlar o desempenho

\begin{tabular}{lcc}
\hline \begin{tabular}{c} 
Quem contrataria para produzir informações \\
que ajudassem no controle das operações e \\
\multicolumn{1}{c}{ avaliação do desempenho da empresa? }
\end{tabular} & Frequência & \% \\
\hline Contador & & 29,2 \\
Economista & 38 & 8,5 \\
Administrador & 11 & 49,2 \\
Advogado & 64 & 0 \\
Nutricionista & 0 & 0 \\
Outro & 0 & 5,4 \\
Não opinaram & 7 & 7,7 \\
Total & 10 & $\mathbf{1 0 0 , 0}$ \\
\hline
\end{tabular}

Fonte: Dados da pesquisa.

Esse resultado pode estar relacionado com a pesquisa realizada por Bernardes e Miranda (2011) sobre o comportamento dos gestores e a utilização das informações econômico-financeira. $\mathrm{O}$ estudo revela que o contador não faz visitas constantes aos seus clientes para acompanhamento da situação financeira e econômica da entidade, não auxiliando seus clientes a gerenciar seus negócios, o que contribui para que o contador seja reconhecido apenas como um profissional direcionado às áreas fiscal e trabalhista.

Esse fato contribui para que mais da metade dos respondentes atribuam importância às informações provenientes da área fiscal $(60,7 \%)$ como úteis ao processo de gestão de suas empresas, conforme a Tabela 5. Esse resultado aponta uma falta de conhecimentos por parte dos gestores da real contribuição gerencial que a Contabilidade pode proporcionar, pois atribuem mais valor às informações sobre impostos e suas implicações. Apenas 21,3\% entendem que as informações contábeis são importantes para o controle gerencial e para a tomada de decisões.

Tabela 5 - Área em que a informação contábil é mais útil na percepção dos entrevistados

\begin{tabular}{lcc}
\hline \multicolumn{1}{c}{$\begin{array}{c}\text { Qual a área em que a informação contábil tem } \\
\text { mais utilidade? }\end{array}$} & Frequência & \% \\
\hline Fiscal & 74 & 60,7 \\
Trabalhista & 11 & 9 \\
Controle gerencial e tomada de decisão & 26 & 21,3 \\
Nenhuma área & 3 & 2,5 \\
Não opinaram & 8 & 6,6 \\
Total & $\mathbf{1 2 2}$ & $\mathbf{1 0 0 , 0}$ \\
\hline
\end{tabular}

Fonte: Dados da pesquisa.

A pesquisa buscou investigar quais relatórios estão sendo fornecidos pela Contabilidade às micro e pequenas empresas da cidade para auxiliá-las no momento da decisão. Para isso, foi feita uma pergunta aberta aos entrevistados sobre quais relatórios, contendo informações gerenciais, recebiam da Contabilidade, conforme Tabela 6. Os resultados apontam que apenas 8,9\% afirmaram receber o Balanço Patrimonial, Balancetes, DRE e o Fluxo de Caixa, ou seja, apenas um pequeno percentual desses gestores tem acesso aos relatórios contábeis. 
Do total, $11 \%$ relataram receber apenas relatórios fiscais e trabalhistas por parte da Contabilidade. No entanto, em algumas conversas com esses gestores, foi possível observar que alguns deles estavam considerando as guias de recolhimento de impostos e contribuições sociais como relatórios, o que na realidade não se trata de relatórios gerenciais, demonstrando que esses gestores não conhecem outras informações que podem ser fornecidas pela Contabilidade.

Tabela 6 - Relatórios provenientes da Contabilidade

\begin{tabular}{lcc}
\hline $\begin{array}{l}\text { Quais relatórios contendo informações gerenciais a respeito } \\
\text { do seu negócio são recebidos da Contabilidade? }\end{array}$ & Frequência & $\%$ \\
\hline Fluxo de caixa, BP, balancetes, DRE & 13 & 8,9 \\
Relatórios fiscais e trabalhistas & 16 & 11 \\
Relatórios de entrada/saída de mercadorias, vendas, contas a & 4 & 2,7 \\
pagar & & \\
Informações recebidas pessoalmente do contador & 3 & 2,1 \\
Nenhum & 48 & 32,9 \\
Outros & 10 & 6,8 \\
Não opinaram & 52 & 35,6 \\
Total & $\mathbf{1 4 6}$ & $\mathbf{1 0 0 , 0}$ \\
\hline
\end{tabular}

Fonte: Dados da pesquisa.

Estudo realizado por Silva et al. (2010) em 55 empresas localizadas na região metropolitana do Recife revelou que, entre as informações contábeis que estão sendo produzidas e disponibilizadas mais frequentemente para os gestores estão a conciliação bancária, o balanço patrimonial e a DRE, o que aponta, pelo menos, o recebimento de alguma informação pela maioria dos empresários, já que, na presente pesquisa, houve um total de $32,9 \%$ que relataram não receber nenhum relatório contábil. Isso revela uma carência na assessoria prestada às MPEs da cidade, onde os contadores não estão proporcionando maior segurança na decisão de seus clientes, permitindo que eles tomem decisões sem nenhuma base financeira sólida.

Ao serem questionados sobre a relevância atribuída à informação contábil na tomada de decisões, $60,3 \%$ dos respondentes consideraram estas como importantes para a empresa. Eles argumentaram que tais informações são necessárias para auxiliar nos negócios, permitindo analisar o passado, fazer previsões, traçar estratégias futuras, favorecer mais confiança e ter uma empresa mais estruturada, além de auxiliar o empresário a nortear um caminho melhor, contribuindo para decisões mais concretas e em tempo hábil, além de balancear os custos e o lucro, garantindo mais segurança.

Tabela 7 - Importância das informações contábeis

\begin{tabular}{lcc}
\hline $\begin{array}{l}\text { As informações recebidas da Contabilidade são } \\
\text { importantes para o suporte à tomada de decisão } \\
\text { que envolva questões econômico-financeiras }\end{array}$ & Frequência & \% \\
\hline Sim & & 60,3 \\
Não & 88 & 14,4 \\
Não opinaram & 21 & 25,3 \\
Total & 37 & $\mathbf{1 0 0 , 0}$ \\
\hline
\end{tabular}

Fonte: Dados da pesquisa. 
A pesquisa demonstra que $14,4 \%$ dos empresários não percebem essas informações como importantes para a tomada de decisões nos negócios, e muitos justificaram que há na Contabilidade uma falta de interesse em oferecer assessoria às empresas; que as informações não são suficientes; que não auxiliam nas questões econômico-financeiras; que a Contabilidade não fornece suporte à tomada de decisões, disponibilizando apenas informações fiscais e trabalhistas.

\subsection{Análise de Frequência Combinada}

Perguntou-se aos gestores se estes manteriam o contrato com o seu contador caso o governo simplificasse o recolhimento dos impostos e contribuições sociais de modo que eles mesmos fossem capazes de calcular e fazer o pagamento. Em contrapartida, questionou-se se esses gestores estariam dispostos a pagar a mais ao contador caso este fornecesse mensalmente relatórios que permitissem gerenciar melhor a empresa e saber como está indo o negócio, conforme a Tabela 8.

Tabela 8 - Frequência combinada

\begin{tabular}{cccccccc}
\hline & \multicolumn{6}{c}{ Disposição a pagar mais ao contador } \\
\cline { 2 - 7 } Disposição a & & Não & Sim (20\%) & Sim (40\%) & Sim (60\%) & Sim $(>60 \%)$ & Total \\
manter o & Não & 7 & 26 & 11 & 3 & 1 & 48 \\
contador & Sim & 23 & 36 & 13 & 5 & 1 & 78 \\
& Total & 30 & 62 & 24 & 8 & 2 & 126 \\
\hline
\end{tabular}

Fonte: Dados da pesquisa.

A pesquisa aponta que $23(18,25 \%)$ manteriam os serviços prestados pelo contador, mas não pagariam mais caso este fornecesse mensalmente relatórios indispensáveis a um melhor gerenciamento em seus processos. Esse resultado confirma que, em alguns casos, devido a recursos financeiros reduzidos, os gestores não estão dispostos a remunerar melhor os serviços prestados pela Contabilidade, preferindo fornecer uma remuneração baixa em troca desses serviços. Serve de alerta o número de $48(38,1 \%)$ que indicaram não manter o contador caso houvesse uma simplificação no recolhimento dos impostos. Isso é mais um indício de que seus contadores prestam apenas serviços contábeis relacionados com o recolhimento dos impostos. Assim, os gestores não têm percebido os profissionais da Contabilidade como fornecedores de outro tipo de informação útil à gestão de seus negócios.

Um ponto importante da pesquisa é que a maioria, 78 destes $(61,9 \%)$, manteria essa assessoria, e $96(76,2 \%)$ estariam dispostos a pagar a mais por informações gerenciais, sendo que o maior número desses indivíduos somente remuneraria com $20 \%$ a mais do que já pagam, sendo esta a remuneração mais baixa constante do questionário, o que reforça a ideia de que os micro e pequenos empresários preferem investir pouco em informações estratégicas que podem auxiliá-los a reduzir as incertezas diárias.

\subsection{Análise de Correlação e Regressão}

Neste tópico, serão apresentados os resultados das análises feitas por meio do nível de correlação e causa existente entre algumas variáveis da pesquisa, de modo a apresentar mais contribuições para o assunto abordado. No Quadro 1, é apresentada a matriz de correlação.

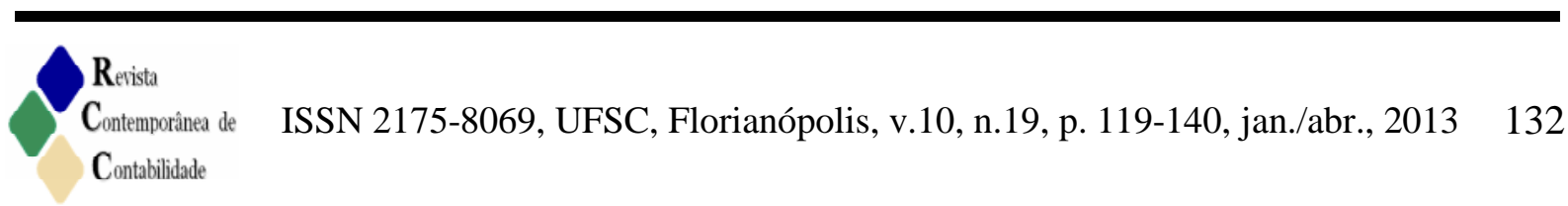


Variáveis apresentadas na análise: V5: Faixa de idade do entrevistado; V6: Grau de escolaridade; V9: Número de Empregados da empresa; V10: Tempo de existência da empresa; V12: Número de computadores existentes na empresa; V13: Tipos de Programas utilizados pela empresa; V14: Nível de informatização na empresa; V22: As informações recebidas da Contabilidade são importantes para o suporte à tomada de decisão que envolva questões econômico-financeiras; V23: As informações contábeis recebidas do seu contador suprem as suas necessidades informacionais? V24: Se o governo simplificasse o recolhimento dos impostos e contribuições de modo que você mesmo fosse capaz de calcular e efetuar o pagamento, você manteria o seu contador? V25: Se o contador produzisse relatórios mensais que permitissem gerenciar melhor a sua empresa e saber como está indo o seu negócio, você estaria disposto/disposta a pagar mais pelos serviços prestados por ele?

Com base nos resultados e na significância estatística dos testes, é possível avaliar a correlação existente entre as variáveis de estudo, o que não implica necessariamente uma relação de causa e efeito entre elas, mas é razoável concluir uma situação de dependência que merece ser estudada pormenorizadamente.

Quadro 1 - Níveis de correlação entre as variáveis

\begin{tabular}{|c|c|c|c|c|c|c|c|c|c|c|c|}
\hline & V5 & V6 & V9 & V10 & V12 & V13 & V14 & V22 & V23 & V24 & V25 \\
\hline V5 & 1 & & & & & & & & & & \\
\hline V6 & -0.09 & 1 & & & & & & & & & \\
\hline V9 & -0.15 & 0.13 & 1 & & & & & & & & \\
\hline V10 & $0.37^{*}$ & 0.14 & 0.16 & 1 & & & & & & & \\
\hline V12 & -0.07 & -0.08 & 0.01 & -0.10 & 1 & & & & & & \\
\hline V13 & -0.08 & 0.01 & $-0.24 * *$ & -0.07 & $0.64 *$ & 1 & & & & & \\
\hline V14 & 0.12 & -0.06 & $-0.25 * *$ & -0.06 & $0.59^{*}$ & $0.57 *$ & 1 & & & & \\
\hline V22 & -0.12 & 0.03 & 0.01 & -0.02 & -0.08 & $-0.24 * *$ & -0.14 & 1 & & & \\
\hline V23 & 0.04 & -0.12 & -0.08 & 0.07 & $0.20 * * *$ & 0.05 & 0.15 & $0.23 * *$ & 1 & & \\
\hline V24 & 0.16 & $-0.20^{* * * *}$ & 0.06 & 0.08 & 0.06 & $-0.19 * * *$ & 0.09 & $0.23 * *$ & $0.23 * *$ & 1 & \\
\hline V25 & -0.02 & 0,18 & 0.02 & -0.04 & $0.25^{* *}$ & $0.25^{* *}$ & $0.17 * * *$ & -0.09 & -0.04 & 0,13 & 1 \\
\hline
\end{tabular}

Nota: * valores significativos $\mathrm{p}<1 \%$; ** valores significativos $\mathrm{p}<5 \% ;{ }^{* * * * *}$ valores significativos $\mathrm{p}<10 \%$

Fonte: Dados da pesquisa.

Os resultados da correlação referentes ao aspecto tecnológico das micro e pequenas empresas sugerem uma relação inversa referente ao número de computadores, dos tipos de softwares utilizados e do nível de informatização da empresa com o número de empregados das empresas. Esse fato pode levantar várias discussões a respeito da utilização da tecnologia nas MPEs como substituto da mão-de-obra, tanto pelo lado da redução dos gastos e melhoria operacional e de gestão, como pelo lado da redução de postos de trabalho que poderão surgir com o aumento da informatização das MPEs. Por outro lado, o fato de ser informatizada não significa necessariamente que os gestores terão os benefícios que a TI pode trazer. Tudo depende de como ela está sendo utilizada na geração de informação.

Outro ponto que merece destaque nas correlações diz respeito à informatização e à relação positiva do número de computadores, tipos de programas e nível de informatização com a disposição de pagar mais aos contadores caso estes resolvessem oferecer informações gerenciais no conjunto dos serviços oferecidos às empresas. Isso, de certa forma, sugere que 
as empresas que têm algum tipo de controle informatizado e utilizam algum nível de geração de relatórios para tomada de decisões consigam enxergar o valor econômico que a informação contábil pode gerar para a empresa.

Também foi observada uma correlação contrária entre tipos de programas utilizados pela empresa e a importância atribuída à Contabilidade, o que demonstra um fato interessante, pois, se as empresas têm a possibilidade de produzir as informações internamente com a utilização de softwares produzidos especialmente para elas, tendem a não atribuir grande importância às informações que a Contabilidade pode gerar. Esse fato se torna preocupante, pois alude que os contadores não têm atribuído importância às informações gerenciais e não instruem seus clientes para essa possibilidade. Desse modo, os gestores acabam por procurar outros meios ou mesmo outros profissionais que possam apresentar essas informações, deixando de valorizar esse que é um dos principais papéis da Contabilidade gerencial.

A análise apontou uma correlação existente entre a disposição em manter o contador, caso o recolhimento dos impostos e contribuições fossem simplificadas, e o grau de escolaridade dos gestores. O resultado negativo revela que quanto maior é a escolaridade, menor é a disposição em manter o contador. Isso denota que os gestores mais instruídos sentem-se mais seguros para realizar os serviços de competência do contador caso estes fossem simplificados. Acredita-se que isso remete a uma visão de desvalorização do profissional contábil.

Para possibilitar inferências sobre relações de causa e efeito entre variáveis a partir das correlações averiguadas, foram estimadas regressões lineares conforme Tabela 9.

Tabela 9 - Influência da TI no número de empregados e disposição a pagar mais por informações de Contabilidade gerencial

\begin{tabular}{|c|c|c|c|c|c|c|c|c|}
\hline \multicolumn{9}{|c|}{$\mathrm{Y}_{\mathrm{i}}=\beta_{0}+\beta_{1} \mathrm{TI}_{\mathrm{i}}+\varepsilon_{\mathrm{i}}$} \\
\hline Depend. & Const. & $\mathrm{NC}$ & $\mathrm{TP}$ & NI & R-Squared $^{\mathrm{a}}$ & Obs. & Estat-F & Robustez $^{a}$ \\
\hline $\mathrm{NE}$ & $6,19^{*}$ & $-0,14$ & & & $0,11 \%$ & 137 & 0,26 & Sim \\
\hline $\mathrm{NE}$ & $10,04 *$ & & $-1,57 *$ & & $5,88 \%^{\mathrm{b}}$ & 134 & $9,30^{*}$ & Não \\
\hline NE & $8,17^{*}$ & & & $-0,93 *$ & $2,77 \%$ & 135 & $6,61^{*}$ & Sim \\
\hline DP & $1,66^{*}$ & $0,22 *$ & & & $5,17 \%$ & 127 & $6,16^{*}$ & Sim \\
\hline DP & $1,56^{*}$ & & $0,27 * *$ & & $3,46 \%$ & 124 & $3,91 * *$ & Sim \\
\hline DP & $1,67^{*}$ & & & $0,22 * * *$ & $2,93 \%$ & 125 & $3,41 * * *$ & Sim \\
\hline
\end{tabular}

Nota: * valores significativos $\mathrm{p}<1 \%$; $* *$ valores significativos $\mathrm{p}<5 \% ;{ }^{* * *}$ valores significativos $\mathrm{p}<10 \%$. ${ }^{a}$ utilizouse a robustez para as regressões que apresentaram heterocedasticidade onde não é possível calcular o R-squared ajustado. ${ }^{\mathrm{b}}$ R-squared ajustado.

Fonte: Dados da pesquisa.

Observa-se relação negativa entre as variáveis de TI e o número de empregados, tanto para a variável TP, quanto para a variável NI. Isso possibilita inferir que quanto mais a MPE utiliza informatização nos seus processos operacionais e gerenciais, menor é o número de empregados. Esse fato é de importância considerável, visto que mostra que as empresas que contam com TI no processo diário podem reduzir seus gastos com mão-de-obra e alerta os empregados e as próprias empresas a investirem na formação tecnológica para se manterem no mercado de trabalho com uma melhora na qualidade dos serviços prestados.

Quando são confrontadas as variáveis de TI e a disposição em pagar mais por informações gerenciais que ajudariam na administração do negócio, é observada uma relação

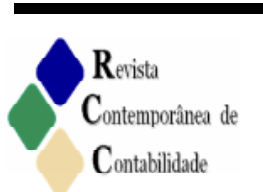

ISSN 2175-8069, UFSC, Florianópolis, v.10, n.19, p. 119-140, jan./abr., 2013 
causal positiva. Essa relação nos leva a refletir sobre a dicotomia existente sobre a prestação de serviços contábeis às MPEs: se, por um lado, esse resultado possibilita inferências que as empresas percebem e necessitam dessas informações, inclusive confirmando o valor econômico da informação; por outro lado, nos mostra que as empresas que prestam serviços contábeis não se preocupam ou, pelo menos, não se atentaram com o fato de que as empresas gostariam de receber essas informações.

Se as empresas estão dispostas a pagar mais por essas informações, é porque as julgam necessárias para a administração do negócio. Desse modo, os escritórios contábeis que se atentarem para a demanda por esses serviços nas MPEs podem ganhar um diferencial competitivo em relação às demais empresas prestadoras de serviços contábeis.

Na Tabela 10, apresentam-se os resultados encontrados sobre a importância dada às informações contábeis pelos gestores das MPEs. Na parte A da Tabela, a relação existente entre a variável dependente IA e as variáveis independentes IS e MC são positivas. Essa relação está de acordo com o esperado, visto que é plausível os empresários acreditarem que as informações suprem as necessidades e estão dispostos a manter o contador, Caso haja simplificação nos aspectos fiscais da empresa, é porque atribuem importância à Contabilidade.

Por outro lado, foi averiguada uma relação negativa entre a importância atribuída à Contabilidade e o nível de informatização, o que, de certo modo, possibilita inferências no sentido que, quando as informações gerenciais são geradas internamente na empresa, os empresários tendem a não valorizar as informações fornecidas pelas empresas contábeis.

Tabela 10- Importância das informações contábeis como um recurso gerencial para suporte a gestão de negócios nas MPEs

\begin{tabular}{|c|c|c|c|c|c|c|c|c|}
\hline \multicolumn{9}{|c|}{ Parte A: Importância atribuída à informação contábil } \\
\hline \multicolumn{9}{|c|}{$\mathrm{IA}_{\mathrm{i}}=\beta_{0}+\beta_{1} \mathrm{NI}_{\mathrm{i}}+\beta_{2} \mathrm{IC}_{\mathrm{i}}+\beta_{3} \mathrm{MC}_{\mathrm{i}}+\varepsilon_{\mathrm{i}}$} \\
\hline $\begin{array}{c}\text { Depend. } \\
\text { IA }\end{array}$ & $\begin{array}{l}\text { Const. } \\
0,73^{*}\end{array}$ & $\begin{array}{c}\mathrm{NI} \\
-0,06 * * * \\
\end{array}$ & $\begin{array}{c}\text { IS } \\
0,2 * * \\
\end{array}$ & $\begin{array}{c}\mathrm{MC} \\
0,17 * * \\
\end{array}$ & $\begin{array}{c}\text { R-squared } \\
10,25 \% \\
\end{array}$ & $\begin{array}{c}\text { Obs. } \\
98 \\
\end{array}$ & $\begin{array}{c}\text { Estat-F } \\
4,69 * \\
\end{array}$ & $\begin{array}{c}\text { Robustez }^{\mathrm{a}} \\
\text { Não } \\
\end{array}$ \\
\hline \multicolumn{9}{|c|}{ Parte B: Manutenção do contador na hipótese de simplificação fiscal } \\
\hline \multicolumn{9}{|c|}{$\mathrm{MC}_{\mathrm{i}}=\beta_{0}+\beta_{1} \mathrm{EG}_{\mathrm{i}}+\beta_{2} \mathrm{NI}_{\mathrm{i}}+\varepsilon_{\mathrm{i}}$} \\
\hline $\begin{array}{c}\text { Depend. } \\
\text { MC }\end{array}$ & $\begin{array}{c}\text { Const. } \\
1,03^{*} \\
\end{array}$ & $\begin{array}{r}E \\
-0,0 \\
\end{array}$ & & $\begin{array}{c}\text { NI } \\
-0,01 \\
\end{array}$ & $\begin{array}{c}\text { R-squared } \\
4,96 \% \\
\end{array}$ & $\begin{array}{c}\text { Obs. } \\
126 \\
\end{array}$ & $\begin{array}{l}\text { Estat-F } \\
3,33 * *\end{array}$ & $\begin{array}{c}\text { Robustez }^{\mathrm{a}} \\
\text { Sim }\end{array}$ \\
\hline
\end{tabular}

Nota: * valores significativos $\mathrm{p}<1 \%$; ${ }^{* *}$ valores significativos $\mathrm{p}<5 \% ;{ }^{* * *}$ valores significativos $\mathrm{p}<10 \%$. ${ }^{a}$ utilizouse a robustez para as regressões que apresentaram heterocedasticidade onde não é possível calcular o R-squared ajustado. ${ }^{\mathrm{b}} \mathrm{R}$-squared ajustado.

Fonte: Dados da pesquisa.

Comparando os resultados com os diálogos feitos com os gestores e empresários, constatou-se que, nos casos de empresas com maior nível de informatização, os escritórios contábeis acabam por ficar responsáveis apenas pela parte fiscal e encargos sociais, e toda parte de geração de informação gerencial fica a cargo dos próprios gestores ou empresários. Ainda nessa linha de análise, considerando os diálogos feitos, percebeu-se que os pequenos empresários dão mais valor à Contabilidade pelo fato de serem mais simples, tanto no aspecto tecnológico quanto em nível de formação escolar e, em muitos casos, não conhecerem a possibilidade de terem informações gerenciais e como poderiam se utilizar delas. 
Esse aspecto é uma das explicações para o resultado encontrado na Parte B da Tabela 10 , onde se constatou que as empresas onde os gestores apresentam um nível de escolaridade maior tendem a não manter os contadores caso haja uma simplificação no recolhimento fiscal da empresa. A variável NI também foi negativa, o que fortaleceria essa ideia, no entanto ela não se mostrou significativa.

De fato, alguns dos gestores detêm formação acadêmica ou tecnológica na área de ciências sociais: mais precisamente 22 técnicos em Contabilidade ou administração; 6 administradores; 12 advogados; e 4 com pós-graduação na área. Desses gestores, percebeu-se que eles conhecem a relevância das informações contábeis no âmbito gerencial. No entanto, adquirem apenas serviços fiscais e societários dos escritórios contábeis, alguns por gerarem as informações necessárias internamente, outros apenas pelo fato de os escritórios contábeis que têm conhecimento não fornecerem esse serviço.

Sucintamente, compreende-se que a preocupação com a qualidade dos serviços prestados traz benefícios econômicos aos contadores e pode ser uma fonte de vantagem competitiva. Entretanto, parte considerável dos micro e pequenos empresários percebe os contadores apenas como profissionais que fornecem serviços direcionados ao recolhimento de impostos e contribuições sociais, não fornecendo assessoria adequada que garanta um suporte às MPEs. Consequentemente, essas empresas detêm níveis de utilização das informações contábeis para fins decisórios relativamente baixos, utilizando, em muitos casos, a experiência ou intuição, o que é preocupante no sentido da continuidade dessas empresas.

\section{Considerações Finais}

Este estudo investigou como os micro e pequenos empresários, ligados ao comércio varejista de Teófilo Otoni, percebem a importância das informações contábeis como um recurso gerencial para o suporte à gestão de seus negócios. Para isso, buscou-se saber qual é a relevância atribuída às informações contábeis no gerenciamento dessas empresas e também no suporte à tomada de decisões, verificando qual é a importância atribuída ao contador e aos serviços contábeis, e se esses serviços garantem um suporte adequado ao processo decisório.

A princípio, os gestores consideraram as informações contábeis importantes no suporte à tomada de decisão, mas, ao se questionar a respeito do recebimento de relatórios por parte da Contabilidade, boa parte dos indivíduos afirma não receber nenhum relatório. Isso explica o grande número de respondentes que apontaram a área fiscal da Contabilidade como a mais importante para o gerenciamento da empresa, pois estes não recebem outras informações contábeis de relevância, não percebendo assim a assessoria contábil como importante no auxílio às suas necessidades gerenciais diárias. Essa percepção é refletida ao indicarem o administrador como o profissional que contratariam para realizar funções de avaliação e controle em suas empresas.

Quanto ao processo decisório dessas empresas, ele se apresenta deficiente, visto que seus dirigentes, na maioria dos casos, confiam mais na própria experiência e, em alguns casos, até mesmo na intuição como recurso para se alcançarem resultados mais corretos.

Assim, parte considerável dos micro e pequenos empresários percebe os contadores apenas como profissionais que fornecem serviços direcionados ao recolhimento de impostos e contribuições sociais. A Contabilidade não tem fornecido uma assessoria adequada que garanta um suporte as MPEs da cidade, e o nível de utilização das informações contábeis para 
fins decisórios é baixo. Para um grupo significativo, o contador não é o profissional qualificado para a elaboração de informações sobre controle e avaliação de desempenho. Por fim, alguns empresários atribuem valor às informações e aos relatórios contábeis, estando até mesmo dispostos a pagar a mais o profissional em troca do recebimento desses relatórios.

Diante desses resultados, é imprescindível que os contadores cumpram com as obrigações não somente fiscais e trabalhistas, mas também gerenciais, pois se percebe que o contador não é visto pelos seus clientes como um indivíduo com competência suficiente para realizar o controle e a análise de desempenho em suas empresas, sendo até mesmo substituído por outros profissionais. Assim, é de extrema importância que prestem uma assessoria completa, por meio da elaboração de relatórios financeiros que permitam ao gestor tomar decisões mais acertadas e em tempo hábil, sendo reconhecidos como profissionais de grande valor a essas empresas.

Quanto às limitações, a pesquisa restringiu-se à cidade de Teófilo Otoni, abrangendo apenas as empresas ligadas ao comércio varejista, não incluindo as empresas ligadas à prestação de serviços e à indústria. Outra limitação no estudo diz respeito às dificuldades de acesso a determinadas empresas da amostra e também ao número de questionários que não foram respondidos. Para novas pesquisas, sugere-se que sejam abrangidos os setores do comércio, da prestação de serviços e da indústria.

\section{Referências}

ALBUQUERQUE, A. F. Gestão estratégica das informações internas na pequena empresa: estudo comparativo de casos em empresas do setor de serviços hoteleiro da região de Brotas. 2004. 209f. Dissertação (Mestrado em Engenharia da Produção) - Curso de Pós-Graduação em Engenharia de Produção, Escola de Engenharia de São Carlos, Universidade de São Paulo, São Paulo, 2004.

ATKINSON, A. A. et al. Contabilidade gerencial. São Paulo: Atlas, 2000.

BATY, G. B. Pequenas e médias empresas dos anos 90: guia do consultor e do empreendedor. São Paulo: Makron Books do Brasil, 1994.

BERNARDES, Danúlia P. G.; MIRANDA, Luiz Carlos. Quatro Histórias da Utilização de Informação Econômico-Financeira nas Micro e Pequenas Empresas: lições para futuros empreendedores. Revista da Micro e Pequena Empresa, Faculdade de Campo Limpo Paulista, v.5, n.3, p. 84-98, set/dez. 2011. Disponível em: $<$ http://www.faccamp.br/ojs/index.php/RMPE/article/view/231>. Acesso em $13 \mathrm{dez}$. 2012.

CANECA, L. R.; MIRANDA, L. C.; RODRIGUES, R. N.; LIBONATI, J. J.; FREIRE, D. R. A Influência da Oferta de Contabilidade Gerencial na Percepção da Qualidade dos Serviços Contábeis Prestados aos Gestores de Micro, Pequenas e Médias Empresas. Pensar Contábil, v. 11. n. 43. p. 35-44. 2009.

CRAGG, P. B.; ZINATELLI, N. The Evolution of Information Systems in Small Firms. Information and Management, v. 29, n. 1 p1-8, july. 1995. 
DIAS FILHO, J. M. A linguagem utilizada na evidenciação contábil: uma análise de sua compreensibilidade à luz da teoria da comunicação, Caderno de Estudos, FIPECAFI, São Paulo, v.13, n. 24, p. 38 - 49, jul./dez. 2000.

EVERETT, J.; WATSON, J. Small Business Failure and External Risk Factors. Small Business Economics. v. 11. n. 4, p. 371-390, 1998.

FLIPPO, E. B.; MUSINGER, G. M. Management. 5. ed. Boston: Allyn \& Bacon, 1970.

HORNGREN, C. T.; SUNDEM, G. L; STRATTON, W. O. Contabilidade gerencial. 12. ed. São Paulo, Prentice Hall, 2006.

IGBARIA, M.; ZINATElli, N.; CRAGG, P.B; CAVAYE, A. L. M. Personal Computing Acceptance Factors in Small Firms: a Structural Equation Model. MIS Quarterly, Management Information Systems Research Center, University of Minnesota, v. 21, n. 3, p. 279-305, sept. 1997.

KNAUP, A. E. Survival and logenvity in the business employment dynamic data. Montly Labor Review. U.S. Bureau of Labor Statistics, v.128, n. 5, p. 50-56, may. 2005.

KRAFTA, L.; FREITAS, H. Ação comercial baseada na gestão da informação de uma pequena empresa de TI. Revista de Gestão da Tecnologia e Sistemas de Informação. v.5, n.3, p. 483-504. 2008.

LEITÃO, P. J. M. Fatores condicionantes do sucesso das micro e pequenas empresas: um estudo do município de Crateús. Sebrae Biblioteca Online, 2009. Disponível em: <www.biblioteca.sebrae.com.br〉. Acesso em 30 novembro de 2012.

LIMA, M. R. S. ; CHACON, M.J.M. ; SILVA, M.C. Uma contribuição a importância do fluxo de informações contábeis no processo decisório das micro e pequenas empresas: uma pesquisa realizada na cidade de recife no estado de Pernambuco. In: Conferencia Internacional de Empreendedorismo Latino Americana, 2004, Rio de Janeiro. Anais... CIPEAL, 2004. CD-ROM.

LUCENA, W. G. L. Uma contribuição ao estudo das informações contábeis geradas pelas micro e pequenas empresas localizadas na cidade de Toritama no agreste pernambucano. João Pessoa, 2004. 114f. Dissertação (Mestrado em Ciências Contábeis) Programa Multiinstitucional e Inter-regional de Pós-graduação em Ciências Contábeis da UNB/ UFPE/ UFPB/ UFRN, João Pessoa, 2004.

MILONE, G. Estatística: geral e aplicada. 2. ed. São Paulo: Cengage Learning, 2009.

MIRANDA, L. C. LIBONATI, J. J.;FREIRE, D. R.; SATURNINO, O. Demanda por serviços contábeis pelos mercadinhos: são os contadores necessários? Contabilidade Vista \& Revista, v. 19, n. 1, p. 131-151, jan./ mar. 2008.

MORAIS, E. F. C. Inteligência competitiva: estratégias para pequenas empresas. Brasília: GH comunicação gráfica Ltda, 1999.

NUNES, L. C. F.; SERRASQUEIRO, Z. M. S. A informação contabilística nas decisões financeiras das pequenas empresas. Revista Contabilidade \& Finanças - USP, São Paulo, n. 36, p. 87-96, set./dez. 2004. 
OLIVEIRA, A. G.; MULLER, A. N.; NAKAMURA, W. T. A utilização das informações geradas pelo sistema de informação contábil como subsídio aos processos administrativos nas pequenas empresas. Revista FAE, Curitiba, v. 3. n. 3. p, 1-12, set./dez. 2000.

PIRES, M. A.; COSTA, F. M.; HAHN, A. V. Atendimento das necessidades de informação para a tomada de decisão em pequenas e médias empresas: análise crítica das informações geradas pela Contabilidade frentes aos seus objetivos - pesquisa exploratória no setor de confecções da Glória-ES. In: SIMPÓSIO FUCAPE DE PRODUÇÃO CIENTÍFICA, 2. 2004, Vitória. Anais... FUCAPE, 2004. CD-ROM.

QUEIROZ, L. M. N. Investigação do uso da informação contábil na gestão das micros e pequenas empresas da Região do Seridó Potiguar. Brasília, 2005. 140f. Dissertação (Mestrado em Ciências Contábeis) - Programa Multiinstitucional e Inter-regional de Pósgraduação em Ciências Contábeis da UNB/ UFPE/ UFPB/ UFRN, Universidade de Brasília, Brasília, 2005.

RAMOS, A. S.; PAULA, C. S.; TEIXEIRA, E. E. M. Análise Comparativa da Qualidade dos Serviços Contábeis prestados pelos Escritórios de Contabilidade em Ipatinga,. In: Semana de Iniciação Científica, 3., 2000, Coronel Fabriciano, Minas Gerais, Anais... Semana de Iniciação Científica, 2000. CD-ROM.

RAMPAZZO, L. Metodologia científica. 3. ed. São Paulo: Edições Loyola, 2005.

SCHELL, G. P. The introduction of management information course goes online. AIS Eletronic Library, 1999. Disponível em: < http://aisel.aisnet.org/amcis1999/330/>. Acesso em: 20 mai. 2010.

SEBRAE. Serviço Brasileiro de Apoio as Micro e Pequenas Empresas. Ambiente empresarial das micro e pequenas empresas gaúchas: os pequenos negócios mostram a sua força na economia. Porto Alegre: SEBRAE-RS, 2009.

SEBRAE. Serviço Brasileiro de Apoio as Micro e Pequenas Empresas. Fatores condicionantes e taxas de sobrevivência e mortalidade das micro e pequenas empresas no Brasil 2003 - 2005. SEBRAE - 2007.Disponível em: 〈http://www.biblioteca.sebrae.com.br〉. Acesso em: 04 out. 2010.

SHELDON, D. Recognizing Failure Factors Helps Small Business Turnarounds. National Productivity Review, v. 13, n. 4, p. 533-541, Autumn. 1994.

SILVA, Daniel J.C. MIRANDA, L. C.; FREIRE, D. R.; ANJOS, L. C. M.. Para que serve a informação contábil nas Micro e Pequenas Empresas? Revista Contemporânea de Contabilidade, UFSC, Florianópolis, v.1, n. 13, p. 89-106, jan/jun. 2010.

SMITH, J. A. The Behaviour and Performance of Young Micro Firms: Evidence from Businesses in Scotland. Small Business Economics, 1999, vol. 13, p. 185-200, nov, 1999. Disponível em: 〈http://journals.kluweronline.com> Acesso em $1^{\circ}$ ago. 2003.

STROEHER. A. M. Identificação das características das informações contábeis e a sua utilização para tomada de decisão organizacional de pequenas empresas. 2005. 159 f. Dissertação (Mestrado em Administração) - Curso de Pós-Graduação em Administração, Escola de Administração da Universidade Federal do Rio Grande do Sul, Porto Alegre, 2005. 
STROEHER, A. M.; FREITAS, H. Identificação das necessidades de informações contábeis de pequenas empresas para a tomada de decisão organizacional. In: III Congresso Internacional de Gestão da Tecnologia e Sistemas de Informação - CONTECSI, 3., 2006, São Paulo. Anais... CONTECSI, 2006. 